\title{
Ambient iCare e-Services for Quality Aging: Framework and Roadmap
}

\author{
Wei-Lun Chang, Soe-Tsyer Yuan \\ National Chengchi University, Taiwan \\ $\{$ wlchang, yuans\}@mis.nccu.edu.tw
}

\begin{abstract}
Owing to the significant scale of the aging population and the cost involved, efforts for driving quality lifestyle of the elderly is crucial. Recently, eCare (electronic Care) has been an important issue of health care that utilizes the Web technologies to improve the quality of health care. However, existing aging services (health care or eCare) are mostly oriented to clinical gerontology or neurophysiology of aging. This paper devises a novel notion called iCare (intelligent Care) which extends eCare (electronic Care) technologies to a domain of ambient e-services that meet the desired quality elements. The objective of iCare is to provide quality e-services to the elderly people anywhere and anytime. We also present the iCare e-services framework that comprises an iCare eservice ontology and an e-service provision quality model. This framework also implies a future roadmap of quality-aging e-services that can be particularly accounted as affectionate technologies.
\end{abstract}

\section{Introduction}

According to the report conducted by Department of Economic and Social Affairs of the United Nations, the growth of aging population around the world will reach to 1,200 millions in the year of 2025 . Seriously, the number will increase to more than 2,000 millions in the year of 2050 [1]. In addition, World Health Organization, (also known as WHO), conducted a research that showed the projection of disabled world population which aged over 65 years nearly increased to 18 millions [2]. Owing to this significant scale of the aging population and the cost involved, quality lifestyle of the elderly is vital.

Quality addressed in this paper comprises the following elements [5]: (1) leading-edge personal care and services that are adaptable to a changing society (2) community involvement that engages in social accountability, volunteer involvement and relationship building (3) consumer-friendly information that provides accessible and understandable information for older adults, families and caregivers (4) consumer participation that engages residents/clients, family members and other consumers in care and services (5) continuous quality improvement that use particular methods to enhance existing services (6) public trust and consumer confidence that commits to a policy of outreach, openness and authenticity to increase public understanding of quality aging services and earn the trust of the consumers.

Based on the desired elements of quality, this paper devises a novel notion called iCare (intelligent Care) which extends eCare (electronic Care) technologies to a domain of ambient e-services that address consumer participation, community involvement and continuous quality improvement. The objective of iCare is to provide quality e-services to the elderly people anywhere and anytime.

The domain of ambient e-services is characterized with an ambient iCare e-services framework (comprising an iCare e-service ontology and an eservice provision quality model). This framework implies a future roadmap of quality-aging e-services that can be particularly accounted as affectionate technologies. The attempted features of the ambient iCare e-services include ambient service accessibility, unbound information reachability, attentive personalized service provision, innovative life-style creation, precious digital memory and seamless social connection. An inspiring motto to describe the iCare roadmap accordingly is "Aging's Life, who cares? iCare".

\section{Foundations of the iCare Framework}

iCare takes into account a variety of dimensions as shown in Figure 1. iCare Dimensions Cube. The environment dimension refers to ambient software and hardware (wired and wireless) required for the deployment of the iCare infrastructure. The physical and relationship dimensions come from the notions addressed in Intel Inventing Wellness Systems [3]. The physical dimension regards the issues of independence, safety, and quality life of aging people. The relationship dimension emphasizes on social network that features meaningful human interactions. A distinct value of iCare rests on the decision dimension, which represents automated collective 
decisions for determining appropriate e-services tailoring to the personal situational context of the elderly people and enabling effective delivery of quality e-services. These decisions would be rendered often by myriad kinds of participant roles involved in the iCare environment automatically and intelligently.

The physical dimension comprises three main areas (promoting healthy behavior, early disease detection, and improved treatment compliance). The aims of this dimension are providing problems prevention in the first place, establishing disease signatures before symptoms become readily apparent, and helping people recover [4].

The relationship dimension, on the other hand, regards a region that engages only the informal caregiving people (e.g., friends, neighbors, etc.). In the other words, iCare, extending from eCare, address consumer participation and community involvement (in the physical and relationship dimensions), in addition to continuous quality improvement of provisioned eservices recommended by the decision dimension.

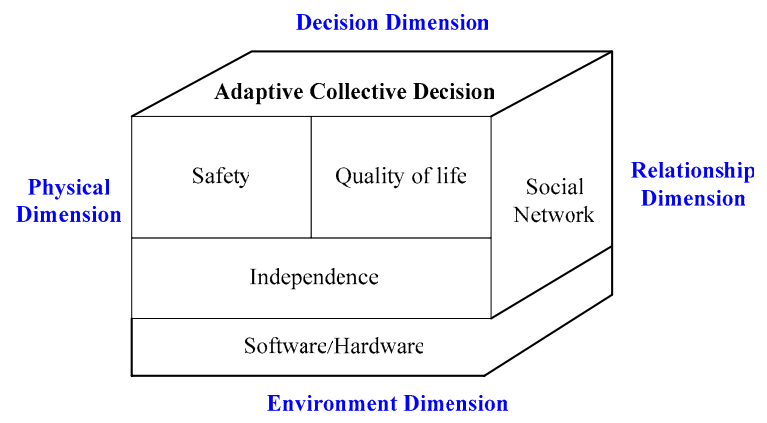

Figure 1. iCare Dimensions Cube

\section{Ambient i-Care e-Services Framework}

\subsection{Taxonomy of iCare e-Services}

The iCare e-services can be categorized into Taking iCare e-Services and Giving iCare e-Services ${ }^{1}$. As follows are the descriptions of these e-services:

- Giving iCare e-Services: this represents a set of e-services that engage an elderly person to contribute to individuals or communities, unfolding two sub-categories of e-services (individual-centric and community-centric).

- Taking iCare e-Services: this represents a set of e-services that engage an elderly person to attain a myriad kinds of resources (physical, mental, combined or informative):

\footnotetext{
${ }^{1}$ For simplicity, this taxonomy is targeted only to the elderly people who are not seriously ill.
}

- Physical: an example of this kind of eservices is telemedicine e-services that provide remote medical assistance.

- Mental: exemplars of this kind of eservices include the Home-Movie eService and connection-oriented e-services.

- Combined (mental plus physical): an example of this kind of e-services is to present to an elderly person therapy entertainment.

- Informative: this refers to the e-services aiming at the provision of myriad kinds of information.

\section{2 iCare e-Service Ontology}

In the iCare ontology (as shown in Figure 2), we discriminate four major concepts (device, home-portal, participant and service). From the concepts of Device and Participant, there will be different hardware and roles involved in the iCare environment. Moreover, Home-Portal is regarded as a smart interface connecting the elderly people with service providers and other kinds of participants. These concepts are further detailed as follows:

- The Service concept is characterized with three high-level attributes (scope, source and type).

- Scope means the degree of heterogeneity and reachability that a service embodies.

- Source indicates the resource origins from which an e-service draws upon.

- Type specifies the forms that an e-service is rendered.

- The Device concept refers to the set of devices (involved in the iCare e-services) that can be divided into two categories (electronic and nonelectronic).

- Electronic means electronic hardware involved in the iCare environment.

- Non-Electronic indicates the non-electronic equipments around the surroundings.

- The Participant concept is characterized with four attributes (role, relationship, profile and preference).

- Role indicates the character played by a participant involved in the iCare environment.

- Relationship means the relationship of a participant to the elderly person.

- Profile specifies the demographic profile of a participant.

- Preference specifies the preference of a participant. 
The iCare service ontology is the first attempt to delimit quality aging e-services engaging both consumer participation and community involvement. This novel and serviceable ontology is believed to be capable of unfolding the beginning of the industry by soliciting myriad kinds of services characterized by the concepts defined in the ontology.

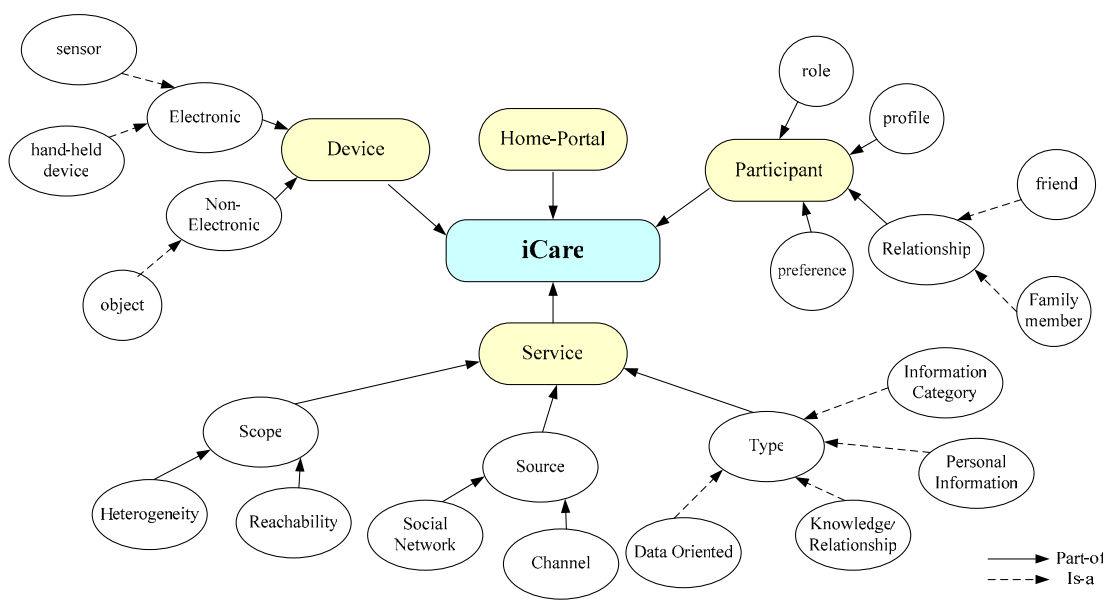

Figure 2. Ontology of iCare

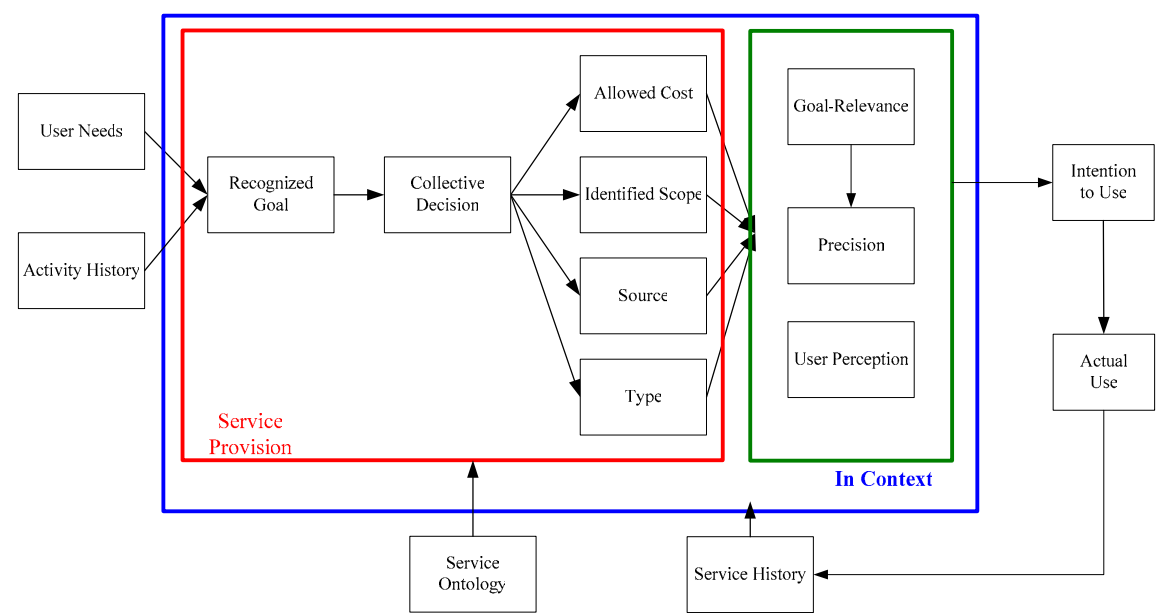

Figure 3. iCare e-Service Provision Quality Model

\section{3 e-Sevice Provision Quality Model}

In this section, an iCare e-service provision quality model (as shown in Figure 3) is proposed so as to serve as a theoretical basis to explain the usage of the iCare e-services, followed by a mathematical version of the model in order to explain how service usage is assessed.

The model proposes that a particular belief, user perception (that can further decompose into two subbeliefs, precision and goal relevance), is the primary driver for service usage. Precision stands for "the degree to which an elderly person believes that using a particular service would improve his or her life quality in depth" and goal relevance for "the degree to which an elderly person believes that using a particular service would improve his or her life quality in width".
Precision and goal relevance then affect jointly to an elderly person's behavioral intention to use the service, which then leads to actual service use. The measures of user perception then include acceptable cost, appropriate scope, useful sources, and appropriate type. In addition, Intention to Use would influence Actual Use of the e-services (with which the service history is subsequently adjusted).

We also presume the existence of the elderly needs that can join with the elderly activity history to facilitate the recognition of the service goal attempted. The recognition of the service goal subsequently identifies $^{2}$ a set of e-service candidates characterized

\footnotetext{
${ }^{2}$ This identification is attained from an automated process of collective decision making (for determining appropriate e-services
} 
by the allowed cost and the identified scope, source and type of the e-services. Selecting an appropriate eservice from the candidate set is then unfolded as an overall consideration of these measurements and an evaluation of service depth and width. The activities of service selection and provision are also grounded on the service ontology and the service history of the elderly person.

\subsubsection{Mathematical Version of the e-Service Provision Quality Model}

This section aims to unfold a mathematical version of the model, which further explain how service usage is assessed and how the feed-back driven process is unfolded. Without loss of generality, the model can be formulized as follows:

(1) $\mathrm{G}=\alpha_{\mathrm{AH}} * \mathrm{~N}$

(2) $\mathrm{S}_{\mathrm{es}}=\mathrm{G}^{*} \beta_{\mathrm{H}} *\left(\mathrm{Co}_{\mathrm{es}}+\mathrm{So}_{\mathrm{es}}+\mathrm{Sc}_{\mathrm{es}}+\mathrm{T}_{\mathrm{es}}\right)$, for a given e-service (es) .

$$
\arg \max _{e s}\left(I_{e s}=U P_{e s} * G R_{e s}\left(1+P_{e s}\right) * \mathrm{~S}_{e s}\right)
$$

In the first formula, $\mathrm{G}$ means the recognized goal, which is attained from the user's needs $(\mathrm{N})$ and can be adjusted by the parameter of activity history $\left(\alpha_{\mathrm{AH}}\right)$. The value of $\mathrm{N}$ ranges from 0 to 1 , which denotes the immediacy of the activities required. The parameter $\alpha_{\mathrm{AH}}$ represents N's weight that is based on the activity history and ranges from 0 to 1 . The second formula assess an e-service (es) and attains a score $\left(\mathrm{S}_{\mathrm{es}}\right)$ (that takes into account the allowed cost $\left(\mathrm{Co}_{\mathrm{es}}\right)$, source $\left(\mathrm{So}_{\mathrm{es}}\right)$, scope $\left(\mathrm{Sc}_{\mathrm{es}}\right)$ and type $\left.\left(\mathrm{T}_{\mathrm{es}}\right)\right)$, further adjusted by service history $\left(\beta_{\mathrm{H}}\right)$ and $\mathrm{G}$. The parameter $\beta_{\mathrm{H}}$ indicates a weight based on the service history, which means the percentage of chance that a given service (es) that is of interest to the elderly person in the past (ranging from 0 to 1$) . \mathrm{So}_{\mathrm{es}}, \mathrm{Sc}_{\mathrm{es}}$, and $\mathrm{T}_{\mathrm{es}}$ denote the values of the matched concepts against the service ontology and the value of $\mathrm{Co}$ is low, medium, or high (respectively represented by $0.1,0.5,1)$.

In the third formula, the intention $\left(\mathrm{I}_{\mathrm{es}}\right)$ of the elderly person to exert a given e-service (es) (characterized by $\mathrm{Co}_{\mathrm{es}}, \mathrm{So}_{\mathrm{es}}, \mathrm{Sc}_{\mathrm{es}}$ and $\mathrm{T}_{\mathrm{es}}$ ) is further evaluated based on the service precision $\left(\mathrm{P}_{\mathrm{es}}\right)$ and the degree of goalrelevance $\left(\mathrm{GR}_{\mathrm{es}}\right)$, further adjusted by the $\mathrm{UP}_{\mathrm{es}}$. The perception $\left(\mathrm{UP}_{\mathrm{es}}\right)$, willingness of adopting the e-service (es), can be appraised ${ }^{3}$ automatically from the service

tailoring to the personal situational context of the elderly people) involving myriad kinds of participants in the iCare environment.

3 This appraisal is based on two assumptions: (1) The elderly person would select the top $\mathrm{m}$ e-services (from the e-service candidate set) to his/her interest in each problem context encountered. (2) These historical selections subsequently reveal the information of interaction history of the elderly person, and the value of UPes can be $0.1^{4}$ (preferring not to use), 0.5 (no comments) or 1 (preferring to use). $\mathrm{GR}_{\mathrm{es}}$ and $\mathrm{P}$ are values ranging from 0.1 to 1 , indicating the width and depth of the e-service (es) respectively with respect to need satisfaction of the elderly person. Furthermore, $\mathrm{GR}_{\mathrm{es}}$ affects $\mathrm{P}$ for that the service width has to be acceptable before the service depth can be addressed.

\section{Conclusion}

Since efforts for driving quality aging is indispensable in light of the pressing aging population and cost involved, innovated e-services addressing quality of aging life are salient and worthy of intensive exploration and research. In this paper, the notion of iCare is defined and implies an innovative and promising industry in the oncoming future. The eservice ontology furnishes the e-service providers with a supporting skeleton to develop their e-services. The e-service provision quality model then empowers the iCare platform to measure the suitability of the eservices. We also provide a roadmap of iCare eservices by exemplifying the possible directions of the e-services to develop. Future research includes evaluating the validity and reliability of the proposed eservice provision quality model.

\section{References}

[1] Population Division, DESA, United Nations. http://www.un.org/esa/population/

[2] Ageing and Life Course of World Health Organization. http://www.who.int/hpr/ageing/publications.htm

[3] Dishman, E., "Inventing Wellness Systems for Aging in Place. IEEE computer Society," Volume 37, Number 5, May 2004, pp.34-41.

[4] Pion, R. J., "E-Care: Made Possible by Technologic Convergence," Proceedings of the 2001 Symposium on Applications and the Internet Workshops (SAINT.01w).

[5] American Association of Homes and Services for the Aging, "Quality First Overview", http://www2.aahsa.org

\footnotetext{
willingness toward e-service adoption on the part of the elderly person.

${ }^{4} 0.1$ (instead of 0 ) is used so as to avoid the situations that 0 cancels out all of the other considerations.
} 